\title{
Health care utilization and health-related quality of life perception in older adults: a study of the Mexican Social Security Institute
}

\author{
Katia Gallegos-Carrillo, MSc,, (I) Carmen García-Peña, PhD, (2) Carlos Durán-Muñoz, MSc, ${ }^{(2)}$ \\ Jyoti Mudgal, PhD, (I) Luis Durán-Arenas, PhD, (3) Jorge Salmerón-Castro, ScD.(I)
}

\begin{abstract}
Gallegos-Carrillo K, García-Peña C, Durán-Muñoz C, Mudgal J, Durán-Arenas L, Salmerón-Castro J. Health care utilization and health-related quality of life perception in older adults: a study of the Mexican Social Security Institute. Salud Publica Mex 2008;50:207-2I7.
\end{abstract}

\begin{abstract}
Objective. To establish how health care service utilization patterns are associated with health-related quality of life (HRQL) perception in older adults. Material and Methods. A cross-sectional study in adults aged 60 years or more was conducted in a random sample of I I50 beneficiaries of the Mexican Social Security Institute (IMSS) in Mexico City during 2003. Health care services utilization was categorized as preventive or curative, which generated six usage profiles. HRQL was measured by means of the SF-36 questionnaire. Analyses of variance and multiple linear regressions were conducted to evaluate the relationship between health care services utilization and HRQL. Results. The use of preventive and curative services has a positive association with HRQL levels. Usage profiles with a prevalence of preventive services have a stronger positive association with HRQL scales. Conclusions. This study suggests a positive association between use patterns for primarily preventive health care services and a better HRQL perception among older adults.
\end{abstract}

Key words: health services/utilization; preventive care; health of the elderly; quality of life; Mexico
Gallegos-Carrillo K, García-Peña C, Durán-Muñoz C, Mudgal J, Durán-Arenas L, Salmerón-Castro J. Utilización de servicios de salud y percepción de calidad de vida relacionada a la salud en adultos mayores: un estudio en el Instituto Mexicano del Seguro Social. Salud Publica Mex 2008;50:207-217.

\section{Resumen}

Objetivo. Determinar cómo distintos patrones de utilización de servicios están asociados con calidad de vida relacionada a la salud (CVRS) de adultos mayores. Material y métodos. Estudio transversal en adultos de 60 años y mayores con muestra aleatoria de I I50 derechohabientes del Instituto Mexicano del Seguro Social (IMSS) en la Ciudad de México en 2003. El uso de los servicios se clasificó en preventivos y curativos, lo que generó seis perfiles de utilización de servicios. La CVRS se midió con el SF-36. Para evaluar la asociación del uso de servicios con CVRS se realizaron análisis de varianza y regresión lineal múltiple. Resultados. La utilización de servicios preventivos y curativos muestra una asociación positiva con CVRS. Los perfiles en que predominan servicios preventivos tienen una asociación positiva más fuerte con escalas de CVRS. Conclusiones. Este estudio sugiere una asociación positiva de los perfiles de uso de servicios predominantemente preventivos con una mejor percepción de CVRS en adultos mayores.

Palabras clave: utilización; servicios preventivos de salud/utilización; salud del anciano; calidad de vida; México

(I) Instituto Mexicano del Seguro Social (IMSS). Cuernavaca, Morelos, México.

(2) Centro Médico Nacional Siglo XXI, IMSS. México DF.

(3) Instituto Mexicano del Seguro Social (IMSS). México DF.

Received on: May 22, 2007 - Accepted on: January 8, 2008

Address reprint requests to: $M$ en $C$ Katia Gallegos Carrillo. Unidad de Investigación en Epidemiología y Servicios de Salud, Morelos. Instituto Mexicano del Seguro Social, Hospital General Regional/Medicina Familiar. Av. Plan de Ayala esquina calle Central s/n. Piso II, número I, col. Chapultepec. 62450 Cuernavaca, Morelos. México.

E-mail:kgallegosc@cis.gob.mx 
$\mathrm{I}_{\mathrm{v}}^{\mathrm{n}}$ recent years, the percentage of older adults in developing countries has increased in an unprecedented way. ${ }^{1}$ The annual growth rate of the elderly population in Mexico was 3.5\% in 2000, which if maintained, the current older-adult population (7.6\%) would double every 19 years and would amount to $28 \%$ of the total Mexican population in 2050. In absolute terms, this means that the number of older adults will equal the number of children by $2034 .^{2}$

This increase in the elderly population represents a major challenge for health care institutions due to the physical, social, and psychological changes that result from a complex morbidity and mortality profile in middle-income countries like Mexico. In addition, aged people have countless needs that health care institutions must address, including infection-related diseases and chronic degenerative illnesses that are common in old age. In fact, the latter are currently among the most frequent causes of morbidity and mortality in Mexico. ${ }^{3}$

This complex disease pattern has resulted in an increasing demand for health care services other than curative services, which have been the main focus of Mexican health care institutions. ${ }^{4}$ Thus, the burden on health care services has become considerably greater and social security institutions are under increasing pressure as they must adjust and adapt their medical units to meet the health care needs of patients with chronic diseases.

Additionally, although the Mexican health care system has been making efforts to increase the number of preventive health care services delivered by public institutions, research based on data from the Mexican Health and Aging Study ${ }^{5,6}$ has documented that there are differences in older adults' use of preventive health care services that relate to health insurance coverage, indicating that insured older adults have better access to preventive health care services. Therefore, this study has focused on the largest public health care institution in Mexico, the Mexican Social Security Institute (IMSS per its abbreviation in Spanish), which covers around $50 \%$ of the Mexican population by providing health care and social services to workers and their families within the formal economy, mainly employed by private firms. Since $75 \%$ of older adults in the IMSS use mainly curative health care services, ${ }^{8}$ over the past several years the IMSS has been developing a series of projects and strategies concerning the delivery of preventive health care services. The most recent project is the Health Integrated Programs (PREVENIMSS) which is aimed both at improving the health status of the population covered by the IMSS and increasing the use of preventive health care and coverage rates. ${ }^{7}$
The IMSS's aging insured population represents a huge challenge to the very essence of its mission as a social security and health care institution. In the years to come, the major difficulties resulting from aging will have to do with the financial impact on the institution -the need to allocate for both pensions and retirement funds for a large aging Mexican generation as well as to provide the wide variety of preventive, assistive, and curative health care services required by elderly people. In view of this, it is crucial for decision-makers to have access to scientific information on which to base their assessments of the impact of health care services utilization on the health and health related quality of life (HRQL) levels of older adults in the IMSS. ${ }^{9}$ It is worth stressing that the quality-of-life measurement, according to the definition of the World Health Organization Quality of Life (WHOQOL), among this population is a valuable indicator. ${ }^{10}$ Indeed, WHO researchers describe quality of life as a comprehensive concept related to the individual's perception of his or her position in life within the context of her or his culture and value system and with relation to his or her goals, expectations, and principles. $^{11}$

The relationship between the use of health care services and HRQL among elderly people has been studied from several perspectives. Some of the research, for example, is focused on HRQL as a predictor of health care utilization. ${ }^{12,13}$ In other words, it has been questioned whether low HRQL levels are associated with high service usage rates, and results have consistently revealed a positive association among numerous populations. ${ }^{14,15}$ However, other studies have found a negative correlation between the use of health care services and HRQL levels in aged people. Studies showing this relationship concern mainly patients with specific chronic conditions, where the HRQL association has been determined with regard to the use of a specific health care service; for example, patients with chronic obstructive pulmonary disease (COPD). These studies show that a higher use of emergency health care services and hospitalization correspond with poorer HRQL levels. ${ }^{16}$ Similarly, negative associations occur between low HRQL and frequent use of curative services. Schoofs, et al. ${ }^{17}$ report that medical support for patients with fibromyalgia and/or chronic fatigue syndrome is inversely proportional to their HRQL.

In addition, a longitudinal study conducted by Kahana with the aim of establishing the impact of proactive behaviors on quality of life concluded that an annual medical checkup had no association with quality of life indicators. ${ }^{18}$ Nevertheless, other studies reveal opposite results with regard to preventive services. A study in 
Mexico suggests that contact with the physician favors higher HRQL, ${ }^{19}$ and this agrees with Gleich's findings that concluded that annual medical checkups may be a factor in maintaining good HRQL among older adults. ${ }^{20}$ To support those associations, other studies have explored the role of preventive home visits to maintain or improve the functional status of the elderly and reduce the use of institutional care.

It is uncertain whether preventive home visits with older people have any impact whatsoever, since some assessments have shown positive and others negative results. For example, based on meta-regression analysis, Stuck et al. conclude that preventive home visits are effective in relatively young target populations with a lower risk of death, ${ }^{21}$ while van Haastregt concludes that no clear evidence exists supporting the effectiveness of preventive home visits for community-dwelling aged people. ${ }^{22}$ Meta-analysis findings indicate that preventive home visits may reduce mortality and hospital admissions but cannot improve the patient's functional status. ${ }^{23}$ As reported, although there are conflicting results among individual studies on preventive home visits, some studies clearly indicate that the use of specific health care services improves the health and functional status of older adults. ${ }^{21}$

However, health systems are currently focused on providing curative rather than preventive health care services for chronic diseases. Hence, conclusive research is still needed to unequivocally establish how patterns of preventive and curative services are associated with HRQL perception.

The objective of the present study is to determine how usage patterns for both preventive and curative health care services are linked with the HRQL perception of elderly people aged 60 and over who use health services at the IMSS, controlling the impact of variables that may alter HRQL. We hypothesized that usage patterns for health care services for patients who seek both preventive and curative services, with a prevalence of preventive services, are associated with higher HRQL perception in older adults.

The hope is that this analysis will contribute to clearly identifying how the various kinds of human and material resources that are continually administered in the delivery of curative and preventive services impact the HRQL of older adults.

\section{Material and Methods}

A survey among insured adults aged 60 and older in the Mexican Social Security Institute in Mexico City was carried out. The sample framework consisted of
131288 individuals who were 60 years or older in 2003, based on the total list of insured individuals from the medical units included in the study, and 1150 subjects who were randomly selected from the total list. At the time of the study, these subjects were not in the terminal stage of a chronic disease and did not exhibit cognitive impairment, the latter being determined by the MiniMental State Examination (MMSE) which was adapted and validated for its administration, in Spanish, to a Mexican population..$^{24}$ Data was collected by means of structured personal interviews conducted by trained surveyors at the individuals' homes, with their written consent. The IMSS Institutional Review Board evaluated and approved the research procedures.

\section{Health-related Quality of Life (HRQL)}

HRQL was assessed using the Medical Outcomes Study 36-Item-Short-Form Health Survey SF-36 ${ }^{25}$ in its Spanish version, which has been validated for Mexican people. ${ }^{26,27}$ This questionnaire consists of 36 items that assess HRQL during the four-week period previous to the administration of the questionnaire by means of eight scales or dimensions: physical functioning (PF); limitations in role activities due to physical health problems $(\mathrm{RP})$; bodily pain $(\mathrm{BP})$; social functioning $(\mathrm{SF})$; general mental health that includes psychological stress $(\mathrm{MH})$; limitations in role activities due to emotional problems (RE); vitality, energy, or fatigue (VT); and general health perception (GH). The PF, RP, and BP scales reflect the physical elements of health; the SF, RE, and MH represent psychological aspects; and VT and GH indicate the subjective perception of health. Each scale measured by this instrument has a transformed score ranging from 0 to 100, where higher values denote better functioning and fewer limitations. SF-36-derived scores do not have a cut-off point to differentiate between good or poor HRQL. ${ }^{25,28}$

\section{Use of services}

The use-of-services variable includes both health and social services at the IMSS and other public and private institutions. By means of direct interviews, information concerning services utilization during the 12 months prior to survey administration was collected. Based on the 1978 WHO Declaration of Alma Ata, ${ }^{29}$ usage of health and social services were grouped into two general categories: preventive services utilization and curative services utilization. The following health and social services classification is based on the health care services delivery scheme at public health institutions in Mexico. 
Preventive Services. Under this classification utilization were considered as the use of at least one of the following services within the past 12 months: 1) Preventive health-care services: consultations in nutrition, use of psychological or preventive odontological or medical services (including immunizations and screening services to detect diabetes, hypertension, and obesity), educational sessions about health, and health promotion activities; 2) Social services: physical activities, health culture courses about personal hygiene and disease prevention, camps for social activities such as cooking, handicrafts, and dance and weekend activities like guided walks, among others. Curative Services. The use of the following services were considered: out-patient consultation with family medicine or specialist physician, emergency and short-hospitalization consultations, auxiliary diagnostic studies (laboratory and/or other auxiliary diagnostic studies), pharmacy, surgery, and hospitalization. Since curative services utilization is quite frequent, we divided it into three groups: 1) nonuse of curative services (no utilization event within the past 12 months), 2) low curative services utilization (use of services once or twice during the past 12 months), and 3) high curative services utilization (on three or more occasions during the past 12 months).

To estimate the health and social service utilization profile, six service utilization profiles, or patterns, ranging from 1 to 6 were developed based on the above mentioned preventive and curative categories, where profile 1 represents the highest service utilization profile and 6 represents the lowest (table I).

In addition, certain co-variables were measured and classified into three groups: first, the socio-demographic variables comprising sex (men [reference level]), age ( $<75$ [reference level]), schooling $(1=$ no formal schooling [reference level], $2=$ elementary, $3=\geq$ junior high), marital status and main activity; second, habits and life style, comprising physical activity and tobacco or alcohol consumption, and; third, the chronic morbidity variable, consisting of the total number of chronic

Table I

Services utilization profiles based on preventive AND CURATIVE SERVICES UTILIZATION CATEGORIES

\begin{tabular}{lccc} 
Type of services utilization & $\begin{array}{c}\text { Non-use } \\
\text { of curative } \\
\text { services }\end{array}$ & $\begin{array}{c}\text { Low curative } \\
\text { services } \\
\text { utilization }\end{array}$ & $\begin{array}{c}\text { High curative } \\
\text { services } \\
\text { utilization }\end{array}$ \\
Preventive services utilization & 1 & 2 & 3 \\
\hline Non-use of preventive services & 4 & 5 & 6
\end{tabular}

diseases previously diagnosed by a registered medical practitioner.

\section{Statistical analysis}

Descriptive analysis was used to identify the general characteristics of the study population and the particularities of health care services utilization by sex. The analysis covered all subjects in the sample, by sex, to determine whether there were differences in the use of preventive and curative services. Analysis of variance was used to analyze differences in the eight HRQL scales versus the six service-utilization profiles, using only the predictor of interest in the model. The analysis included the whole sample of individuals not affected by diabetes and two or more chronic diseases. Bivariate analysis was used to examine the impact of each utilization profile on HRQL. Finally, multiple linear regression models were applied to analyze the independent effect of six service-utilization profiles on each HRQL scale, adjusting for the remaining co-variables. To control potential confounding with regard to health care services utilization and morbidity, the same linear regression analyses were made with all the participants' data and including only patients without diabetes and two or more chronic diseases.

\section{Results}

Of the total sample, 1085 individuals were included in our study (58\% women). The average age was 71 years with no significant differences between men and women. Regarding marital status, almost 78\% of the men were married versus $58 \%$ of the women; $18 \%$ of the men were widowed, compared to $37 \%$ of the women $(p<0.05)$. As for schooling, 20\% of the sample reported no formal schooling, without any differences by sex. Data about their main activity showed that $16 \%$ of men work outside the home compared to $6 \%$ of women. In addition, $65.5 \%$ of men and $11 \%$ of women were retired or pensioned $(p<0.05)$. Differences in the chronic comorbidity categories between men and women were not found (table II).

Seventy percent of the subjects reported having used health services at IMSS Family Medicine Units. With regard to preventive services, use of health education and promotion services was low. As for social services, only half the people using social-type services did so at IMSS facilities.

Curative services utilization was concentrated in out-patient consultations as well as in family medicine and medical specialty $(87.56 \%$ ) consultations, followed 
Table II

General characteristics of StUdy population by SEX

\begin{tabular}{|c|c|c|c|}
\hline Variables & $\begin{array}{c}\text { Men } \\
n(\%) \\
n=455(41.9 \%)\end{array}$ & $\begin{array}{c}\text { Women } \\
n(\%) \\
n=630(58.1 \%)\end{array}$ & $p$ value \\
\hline Age* & $71.9 \quad(7.6)$ & 7I.3 (7.6) & $0.221^{\ddagger}$ \\
\hline \multicolumn{4}{|l|}{ Marital status } \\
\hline Married & 353 (77.6) & $365(57.9)$ & $0.000^{\S}$ \\
\hline Non-married & $21 \quad(4.6)$ & 32 (5.I) & \\
\hline Widowed & 81 (I7.8) & $233(37)$ & \\
\hline
\end{tabular}

Educational level

\begin{tabular}{lrrr} 
No formal education & $85(18.7)$ & $136(21.6)$ & $0.316 \S$ \\
\hline Primary & $234(51.4)$ & $328(52.1)$ & \\
\hline$\geq$ Secondary & $136(29.9)$ & $166(26.3)$ &
\end{tabular}

Main activity

\begin{tabular}{lcrrr} 
Works outside home & $73(16)$ & $37(5.9)$ & $0.000 \S$ \\
\hline Homemaker & $78(17.1)$ & $519(82.4)$ & \\
\hline Retired or pensioned & $298(65.5)$ & $69(10.9)$ & \\
\hline Permanently disabled & $6(1.3)$ & $5(0.8)$ &
\end{tabular}

Physical activity

\begin{tabular}{llll} 
Yes & $116(25.5)$ & $137(21.7)$ & $0.150 \$$ \\
\hline No & $339(74.5)$ & $493(78.3)$ &
\end{tabular}

Alcohol consumption

\begin{tabular}{llll} 
Yes & $204(44.8)$ & $109(17.3)$ & $0.000 \$$ \\
\hline No & $25 I(55.2)$ & $521(82.7)$ &
\end{tabular}

Tobacco consumption

\begin{tabular}{rrrr} 
Yes & $112(24.6)$ & $30(4.8)$ & $0.000 \S$ \\
\hline No & $343(75.4)$ & $600(95.2)$ &
\end{tabular}

Chronic comorbidity

\begin{tabular}{lrrr} 
None & $97(21.3)$ & $125(19.8)$ & $0.838 \S$ \\
\hline I chronic disease & $172(37.8)$ & $242(38.4)$ & \\
\hline$>2$ chronic diseases $\quad 186(40.9)$ & $263(41.7)$ \\
& & \\
* Mean and Standard deviation & \\
₹ T test (men versus women) \\
\& Pearson Chi ${ }^{2}$ (men versus women)
\end{tabular}

by pharmacy services utilization (66.08\%). Roughly $1 \%$ of older adults had undergone surgery during the previous year. The use of several curative services at other public or private institutions was around $1 \%$, with the exception of out-patient specialty consultations which was roughly $5 \%$ (table III).
When assessed the mean values in all the HRQL scales, it was clear that the highest HRQL values are found in profile 1 users -i.e. preventive services users and non-users of curative services- while the lowest values across all the HRQL scales are found in profile 6 -i.e. non-use of preventive services and high curative services utilization. The difference in the HRQL scores observed between profile 1 and profile 4 , non-use of preventive services and non-use of curative services show that similar differences are present in all the HRQL scales, particularly in those for physical problems.

The mean difference between both service utilization profiles exceeded 28 points (table IV). It is clear that the elderly using mainly preventive services reported higher HRQL levels. These positive associations in favor of preventive health care utilization are prevalent in older adults without diabetes and two or more chronic diseases (table IV). It is worth stressing that the same analysis of health service utilization profiles and HRQL by sex did not show statistically significant differences, suggesting that the perception of each HRQL scale differs for men and women according to the pattern of health care services utilization and not according to sex (data not shown).

Multiple linear regression analyses corroborate the association between the six service utilization profiles and HRQL as well as the impact of the other variables on this relationship. In addition, certain association patterns exist for HRQL scales and health care service utilization profiles: for physical functioning, social functioning, physical problems, and bodily pain, non-use of preventive and curative services has a slightly higher association with these HRQL scales, whereas for patients without diabetes or two or more chronic diseases the profile for preventive health care utilization and nonuse of curative services has the strongest association. Likewise, in the vitality scale the latter profile presents the highest association both in the sample population and in the group without comorbidity (table V).

Also, in the scales related with mental HRQL dimensions, i.e. emotional problems and mental health, a combination of preventive services with some degree of curative services utilization resulted in higher scores (table V).

Finally, in the general health scale, health service utilization profiles had no statistically relevant association. Nevertheless, when the analysis was carried out among patients without diabetes and two or more chronic diseases, a combination of preventive and curative services utilization was associated with a better general health perception $(p<0.05 B=0.22)$ (table V).

The standardized regression coefficients for both SF-36 and socio-demographic factors are shown in table 
Table III

Characteristics and frequencies of PReVentive and curative health Services Utilization, 2003

Total $n(\%) \quad$ Men $n(\%) \quad$ Women $n(\%)$

$1085(100) \quad 455(41.9) \quad 630(58.1)$

Preventive health services utilization in the IMSS* or other public or private institutions within the past 12 months

\begin{tabular}{|c|c|c|c|}
\hline No & $688(63.4)$ & $297(65.3)$ & $391(62.1)$ \\
\hline Yes (use of at least one service) & $397(36.6)$ & $158(34.7)$ & $239(37.2)$ \\
\hline Consultation at the IMSS nutrition service & $22(1.9)$ & $6(1.3)$ & $16(2.5)$ \\
\hline Consultation at the IMSS psychological service & $13(1.2)$ & $6(1.3)$ & 7 (I.I) \\
\hline Consultation at the IMSS odontological service & $22(2.0)$ & II (2.4) & I (I.7) \\
\hline IMSS preventive medicine & $20 I(18.5)$ & $76(16.7)$ & $125(19.8)$ \\
\hline IMSS educative sessions for health ${ }^{\ddagger}$ & $31 \quad(2.9)$ & $13 \quad(2.9)$ & $18 \quad(2.9)$ \\
\hline IMSS health promotion activities $\S$ & $5(0.4)$ & I $(0.2)$ & $4(0.6)$ \\
\hline IMSS social services & $61 \quad(5.6)$ & $19 \quad(4.2)$ & $42 \quad(6.7)$ \\
\hline Social services in other public and private institutions & $13(11.9)$ & $62(13.6)$ & $68(10.8)$ \\
\hline
\end{tabular}

Curative health services utilization in the IMSS or other public or private institutions within the past 12 months

\begin{tabular}{|c|c|c|c|}
\hline No & $286(26.4)$ & $123(27.0)$ & $163(25.9)$ \\
\hline Low utilization (Use I-2 of the services) & $368(33.9)$ & $150(33.0)$ & $218(34.6)$ \\
\hline High utilization (Use 3 or more of the services) & 431 (39.7) & $182(40.0)$ & $249(39.5)$ \\
\hline Out-patient consultation with IMSS family medicine or specialist physician & $950(87.6)$ & $390(85.7)$ & $560(88.9)$ \\
\hline IMSS emergency consultation & $99(9.1)$ & $47(10.3)$ & $52(8.2)$ \\
\hline Short IMSS emergency hospitalization & $41 \quad(3.8)$ & $17(3.7)$ & $24(3.8)$ \\
\hline IMSS laboratory studies & $364(33.5)$ & $146(32.1)$ & $218(34.6)$ \\
\hline Other IMSS auxiliary diagnostic studies & $230(21.2)$ & $91(19.9)$ & $139(22.1)$ \\
\hline IMSS pharmacy service & $717(66.1)$ & $301(66.1)$ & $416(66.0)$ \\
\hline IMSS surgery & $10 \quad(0.9)$ & $3(0.7)$ & $7(1.1)$ \\
\hline IMSS hospitalization & $29 \quad(2.7)$ & $10(2.2)$ & $19 \quad(3.0)$ \\
\hline Specialist consultation in other public or private institutions & $44 \quad(4.1)$ & $23 \quad(5.0)$ & $21 \quad(3.3)$ \\
\hline Emergency consultation in other public or private institutions & $6(0.5)$ & $3(0.7)$ & $3(0.5)$ \\
\hline Laboratory studies in other public or private institutions & $9 \quad(0.8)$ & I $(0.2)$ & $8 \quad(1.3)$ \\
\hline Other auxiliary diagnostic studies in other public or private institutions & $4 \quad(0.4)$ & I $(0.2)$ & $3(0.5)$ \\
\hline Surgeries in other public or private institutions & $5(0.5)$ & $2(0.4)$ & $3(0.5)$ \\
\hline Hospitalization in other public or private institutions & $3(0.3)$ & I (0.2) & $2(0.3)$ \\
\hline
\end{tabular}

* IMSS: Mexican Institute of Social Security

¥ This includes educative sessions for patients with diabetes, hypertension, or obesity about self-esteem, stress control, and violence

$\S$ This includes yoga, dance, and handicrafts

V. As age increases, HRQL perception becomes poorer. General health and social functioning scales showed slight differences by sex, with female being associated with higher scores. In addition, higher schooling was associated with higher HRQL. Finally, it is worth mentioning that in the regression models, variables like insurance type did not indicate any association with HRQL scales, after stratified analysis and like-adjusted variables.

\section{Discussion}

This study suggests a positive association between predominantly preventive health service utilization patterns and better HRQL perception among the elderly. Before discussing the specific findings of this study, some general aspects of the study population and the use of health care services should be outlined. 


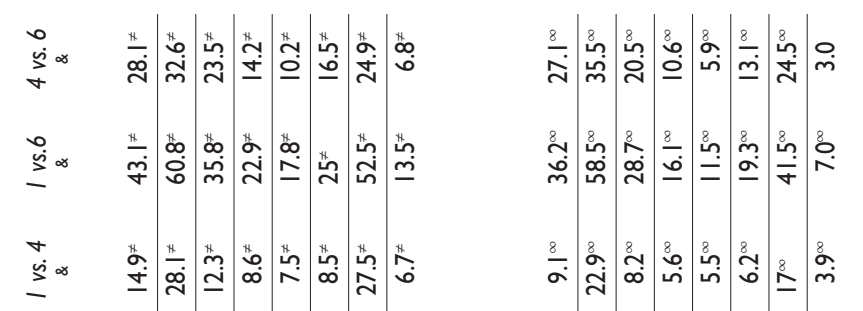

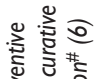

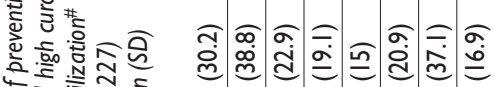

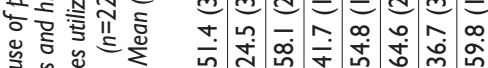

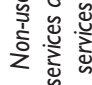

$\frac{2}{2}$

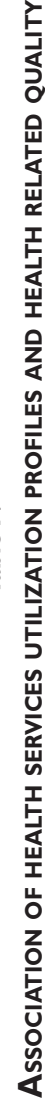

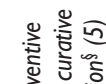

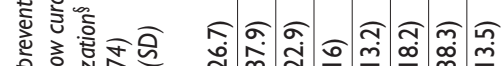

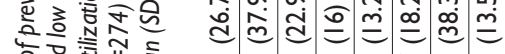

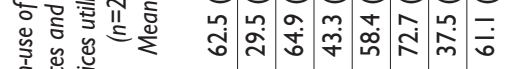

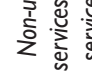

崩

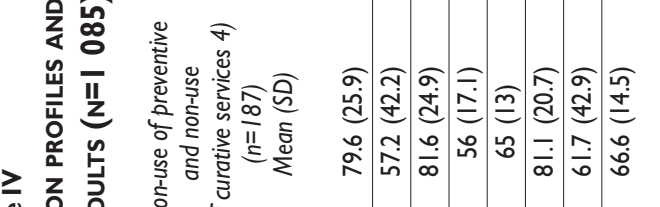
文

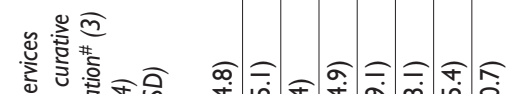

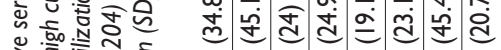

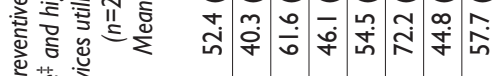
离产产离

ब.

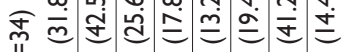

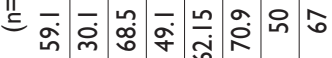

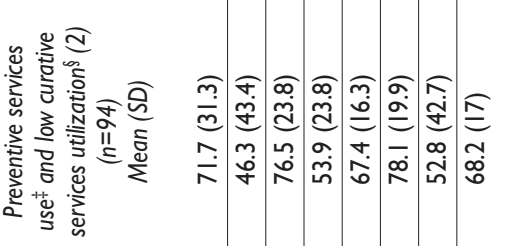

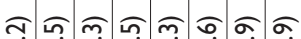

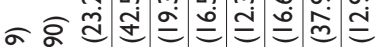

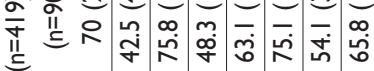

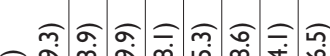

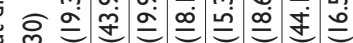

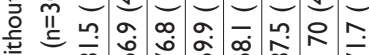

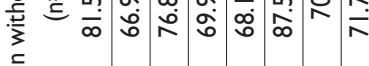

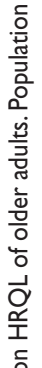

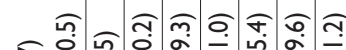

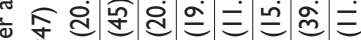

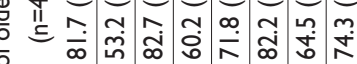

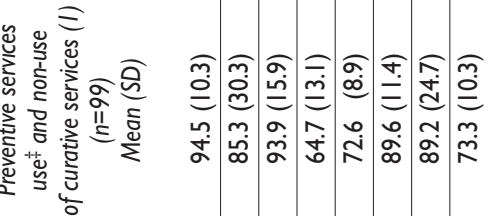

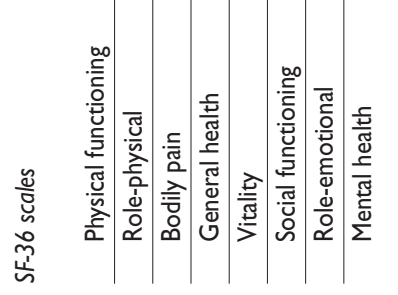

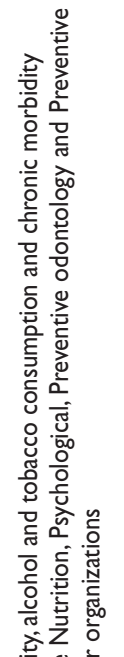

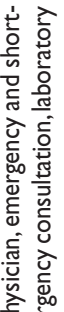

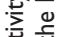

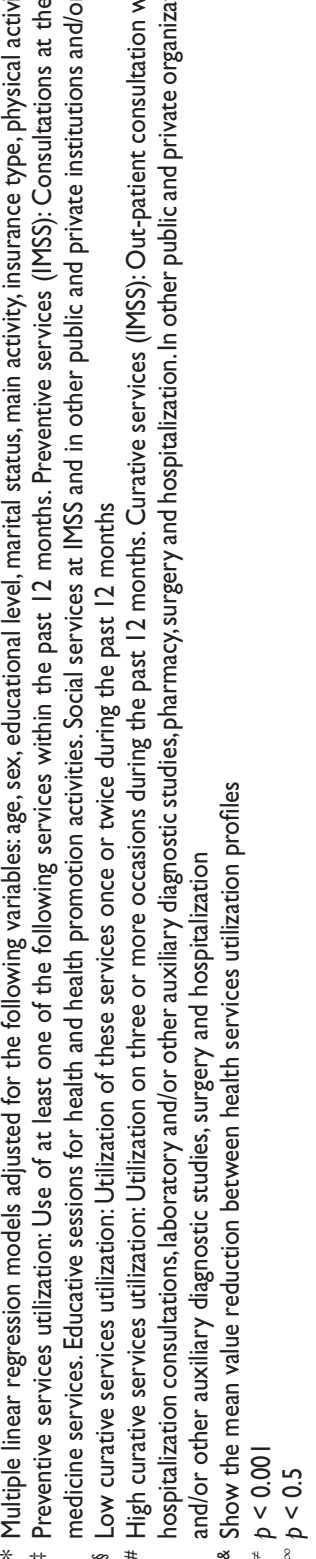

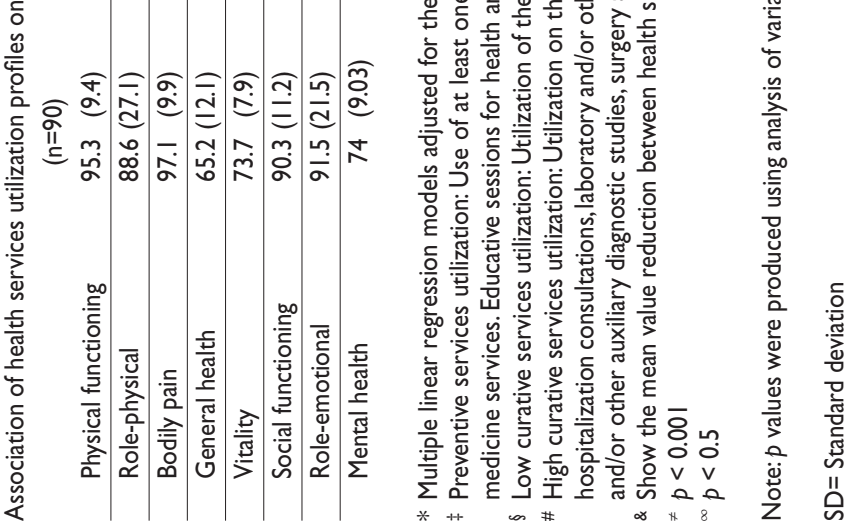




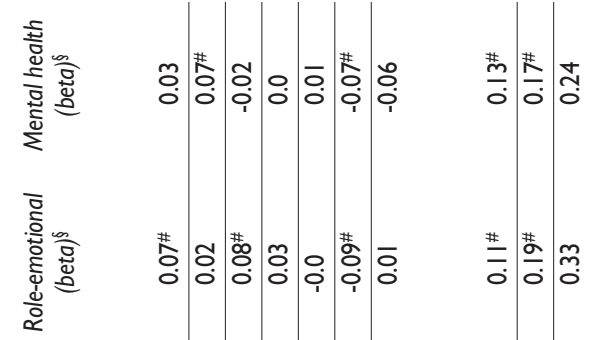

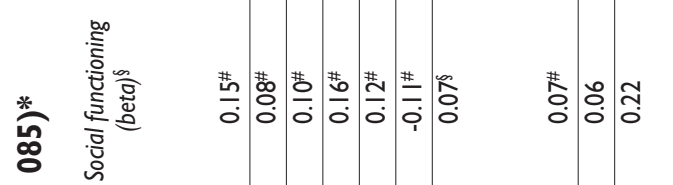

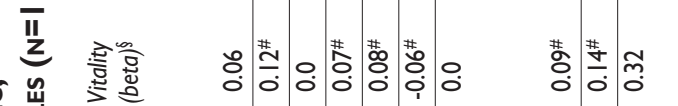

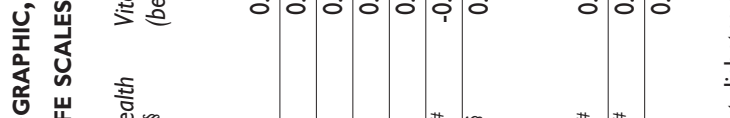

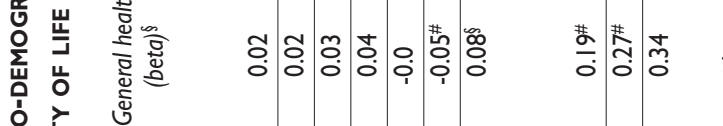

ò

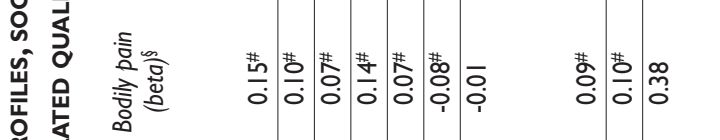

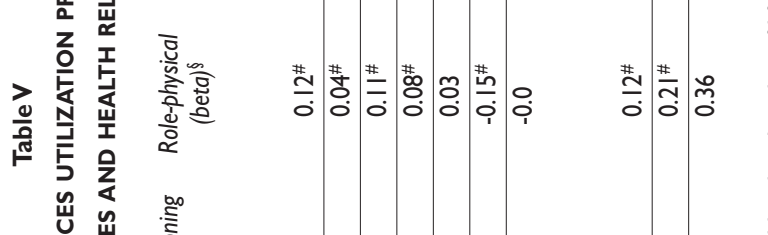

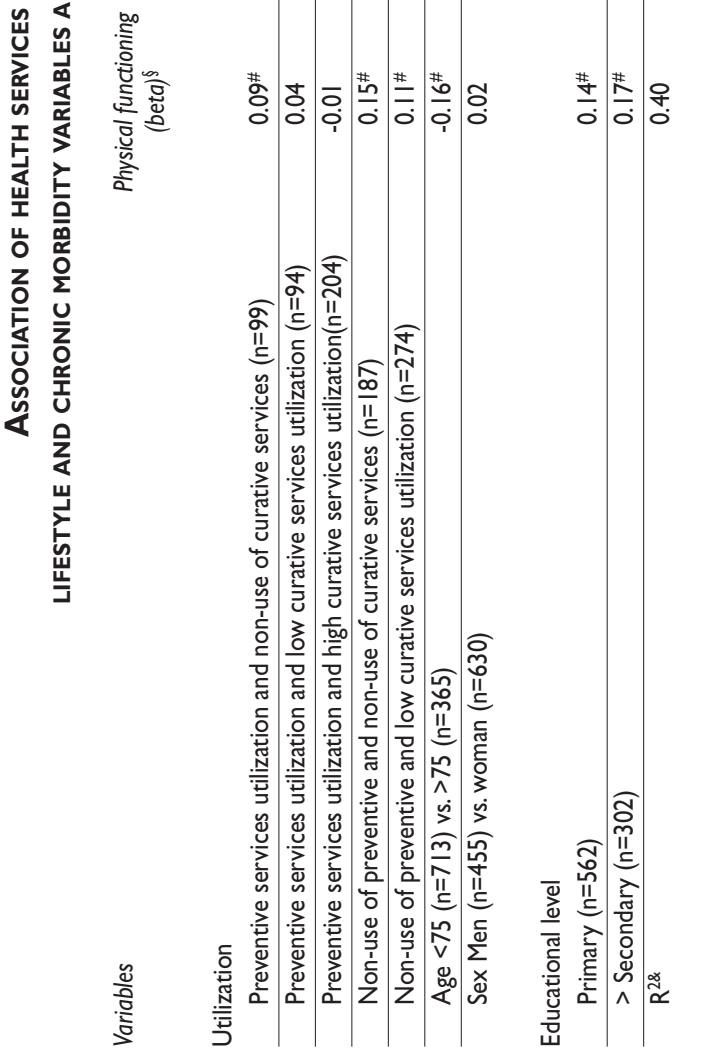

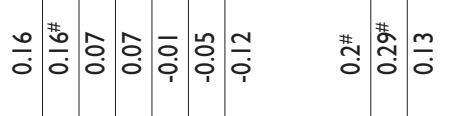

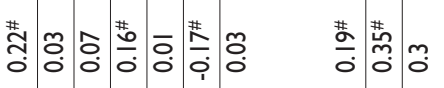

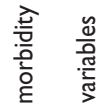

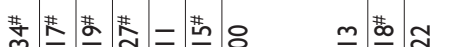

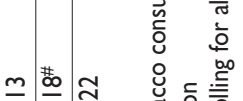

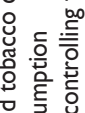

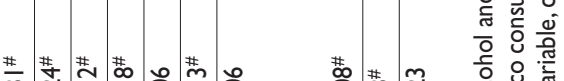

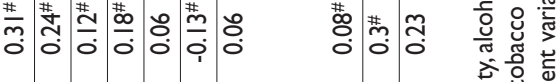

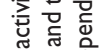

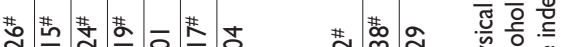

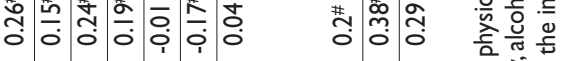

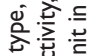

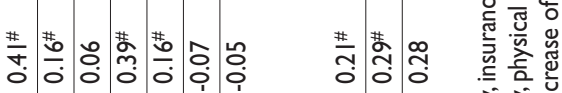

要

窟密

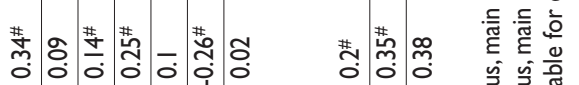

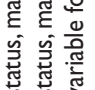

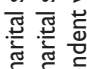

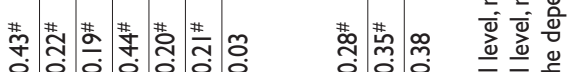

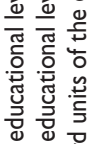

希希 产

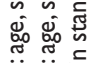

它

旅

更

응 응 든

政

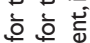

过定

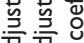

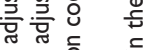

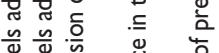

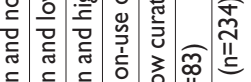

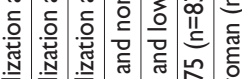

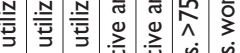

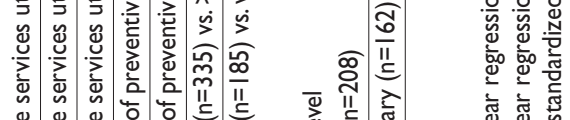

con

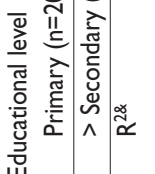


The socio-demographic characteristics of older adults covered by the IMSS differ to a certain extent from those of the rest of the Mexican population. For example, when comparing the results of this study with findings from the 2000 National Health Survey (NHS-2000) and the Mexican Health and Aging Study, the average age of elderly IMSS-insured patients is slightly higher, the percentage having no formal schooling is smaller, ${ }^{30,31}$ and since the uninsured population continues working longer than elderly IMSS beneficiaries, there are more retired elderly people among those insured by the IMSS than among the uninsured population. These findings are consistent with data obtained from the analysis of the IMSS population included in the NHS-2000. ${ }^{32}$

It is worth noting that when results for frequency of health care services utilization were compared with the findings of other studies carried out among the Mexican population, the proportion of patients using preventive care services is smaller than that reported by Wong and Díaz and Pagan, et al. ${ }^{5,6}$ We are aware that these findings could be limiting to our results and that the preventive services association, therefore, may be underestimated. According to Borges and Dantes, low preventive service utilization is reflected in an increase in curative services utilization. ${ }^{33}$ However, the frequency of services utilization is consistent with the findings of a longitudinal study of IMSS-insured aged people living in Mexico City. ${ }^{8}$ As for the differences in the use of preventive care services by men and women identified in a previous paper, ${ }^{5}$ they are not corroborated by our study since we did not find relevant sex-based differences in the use of preventive and curative care services. We should stress, though, that directly contrasting both series of findings is inadvisable due to differences in methods for measuring the variable for preventive services utilization.

Finally, in relation to the pattern of curative services utilization by older adult patients in the IMSS, we observe that our findings match the high frequency rates of health services utilization that were reported by the NHS-2000 analysis of IMSS-insured population, especially in the case of out-patient consultation services and hospitalization. ${ }^{34}$

The overall findings on the positive association between preventive care utilization and HRQL in older adults are in agreement with both the work of Stuck, et al. ${ }^{21}$ who found a positive impact of home visits on the prevention of nursing home admissions and functional decline, and that of Elkan, et al. ${ }^{23}$ who also reported a positive impact of home-based support for older people on their mortality and admission to long-term institutional care. Obviously, the objective of this study differs from those of these two meta-analyses of controlled trials. Still, our study shows a remarkable association for these kinds of curative and preventive practices in Mexico and that patterns may be established by means of a cross-sectional study.

These findings are relevant because they make a case for preventive medicine as a potentially effective intervention for older adult populations, and they are in agreement with the work of Theander, et al., on Swedish older adults, concerning the link between preventive services and HRQL. ${ }^{35}$

Prior research in this area has shown that poor HRQL is associated with health services utilization. ${ }^{14,15}$ However, the main focus of this study was to identify the impact of services utilization patterns on elderly HRQL. In this regard, for example, Damian, et al..$^{36}$ concluded that recent contact with a physician was associated with poor health. These results concur with those of other studies that adjusted for the patient's functional capacity. ${ }^{37,38}$ Yet, these studies did not discriminate between preventive and curative services utilization and focused only on the functional aspects of HRQL.

In addition, this study confirms the assumptions raised by Kahana, et al. in 2002 with regard to the role of older adults' preventive and curative behaviors in their HRQL. ${ }^{18}$ The six profiles used to measure services utilization in our study were based on the conceptual model of successful aging by Kahana \& Kahana, ${ }^{39}$ in which proactive preventive and curative behaviors represent an important part of the model.

Despite being a cross-sectional study, the stratified analysis among patients with and without chronic diseases partially settled the temporality issue associated with cross-sectional design. The results presented showed the association between health care utilization patterns and HRQL in five of the eight scales used in this study, namely: physical problems, bodily pain, vitality, emotional problems, and mental health scales. A better HRQL perception was found among individuals that made use of preventive services. Also, when older people with diabetes and two or more chronic diseases were excluded, our results were still consistent. Thus, the chronic conditions related to health status are not explained by our findings, since after reducing the potential confounding arising from morbidity that could bias the utilization pattern, we found a clear association between preventive health care services utilization and a higher HRQL perception, while the correlation of curative services utilization remained unchanged. The standardized regression coefficients related to preventive services are higher than those for other utilization profiles, except for the physical functioning scale, in which the non-use of preventive and curative services profile shows a higher coefficient. This finding could be accounted for by the fact that non-users of preventive 
and curative services tended to be younger, as has been documented by other studies and our own findings. Generally speaking, older age is an element that has a negative impact on quality of life perception ${ }^{40}$ and those not using health services are thus likely to present fewer health problems and may have a better HRQL. It is worth noting that even though scores were higher in the profiles of non-users of preventive and curative services than in profiles that included curative users, they were considerably lower than those for profile 1 (users of preventive services only).

The number of chronic diseases represents a relevant variable: $79.53 \%$ of study subjects reported having at least one previous medically diagnosed chronic disease, close to the $81.5 \%$ found by Damian. ${ }^{36}$ It is well known that chronic diseases have an effect on the HRQL perception of non-hospitalized patients in health

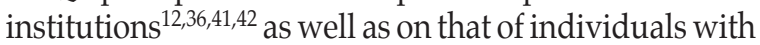
a specific diagnosis. ${ }^{43}$ Several studies have shown that low HRQL is associated with higher health services utilization among older adults, ${ }^{12,14}$ which points to the fact that this relationship is a complex one to assess, even more so when there are important differences in the health care system, together with the socio-economic and cultural characteristics of developing countries such as Mexico. Thus, the relationship between chronic morbidity, HRQL, and health services utilization could be determined according to the levels of each one. In this regard, our findings show that when the impact of chronic diseases on older adults' HRQL is constant, preventive services utilization is positively associated with a better HRQL perception.

\section{Conclusions}

Health-related quality of life is important to assess the impact of preventive and curative services utilization on health. It provides a comprehensive measure for several health and well-being dimensions and is particularly useful in populations affected mainly by chronic diseases.

This study found that visits by older adults to medical care units for preventive services utilization are associated with a better perception in all HRQL dimensions.

The use of curative services is also related, to a lesser extent, to a better HRQL perception, and, as this study suggests, is associated with the physical functioning, social functioning, bodily pain, and vitality HRQL scales in the elderly; an association that is significant after controlling for the effects of chronic diseases that these patients suffer from and reducing potential confounding.
These results are relevant as they show that it may be desirable to abandon the morbidity-centered vision that limits the assessment of the impact of health programs, particularly those concerning older adults with chronic diseases. Our main purpose should be to slow down disease progression and preserve a good HRQL level in older adults.

Health policy planning and health program development for the elderly should acknowledge the relevance of moving forward from curative to preventive services and from medical services to social services. Only in this way may comprehensive health care services for older adults be developed, with a view towards addressing the complex needs of this growing population in our societies.

Since 2003, efforts to increase the coverage of preventive care services at the Mexican Social Security Institute have succeeded due to Health-Integrated Programs (PREVENIMSS), that has as one of its main components the health of older adults. Therefore, in the coming years, it would be crucial to undertake research aimed at establishing the impact of the increase in PREVENIMSS coverage on the use of both preventive and curative health care services and on the HRQL of older adults in the IMSS.

\section{Acknowledgements}

This study was made possible thanks to the IMSS2002/047 research grant bestowed by the National Health Research Council of the Mexican Social Security Institute (IMSS).

\section{References}

I. Dominguez LJ, Galioto A, Ferlisi A, Pineo A, Putignano E, Belvedere M, et al.Ageing, lifestyle modifications, and cardiovascular disease in developing countries. J Nutr Health Aging 2006; 10: 143 - 149.

2. Consejo Nacional de Población. Estimaciones y proyecciones del Consejo Nacional de Población 2002. Mexico City: CONAPO, 2002. 3. World Health Organization. Innovative care for chronic conditions: building blocks for action. Geneva:WHO, 2002.

4. Partnerships for Health Reform Project. Cuentas Nacionales de Salud: México. Informe de Iniciativas Especiales II. Bethesda, MD:Abt Associates, Inc., 1998.

5.Wong R, Díaz JJ. Health care utilization among older Mexicans: health and socioeconomic inequalities. Salud Publica Mex 2007;49(suppl 4): S505-S5I4.

6. Pagan JA, Puig A, Soldo BJ. Health insurance coverage and the use of preventive services by Mexican adults. Health Econ 2007;12:1359-1369. 7. Mejía-Rodríguez I, Cisneros-Salazar M, Rosales-Piñón A, Reyes-Niño S, Reyes-Morales H, Gutiérrez-Trujillo G. ENCOPREVENIMSS 2003, 2004 y 2005. 3. Avances en los Programas de Salud de la Mujer, del Hombre y del Adulto Mayor. Rev Med Inst Mex Seguro Soc 2006;44(suppl I):S43-S54. 
8. Reyes-Frausto S. Population ageing in the Mexican Institute of Social Security: Health policy and economic implications. Mexico City: IMSS FUNSALUD, 200I:I43-155.

9. Testa MA, Simonson DC.Assessment of quality of life outcomes. N Eng J Med 1996;334:835-840

10. Centers for Disease Control and Prevention. Quality of life as a new public health measure. Behavioral Risk Factor Surveillance System, 1993. Morb Mortal Wkly Rep 1994;43:375-380.

II.The WHOQOL Group. The World Health Organization Quality of Life Assessment (WHOQOL): Position paper from the World Health Organization. Soc Sci Med 1995; 10: I 403-1409.

12. Lam CL, Fong DY, Lauder IJ, Lam TP.The effect of health-related quality of life (HRQOL) on health service utilisation of a Chinese population. Soc Sci Med 2002;55:1635-1646.

I3. Parkerson GR Jr, Hammond WE, Michener JL, Yarnall KS, Johnson JL. Risk classification of adult primary care patients by self-reported quality of life. Med Care 2005;43: 189-193.

I4. Miilunpalo S,Vuori I, Oja P, Pasanen M,Arponen H. Self-rated health status as a health measure. The predictive value of self-reported health status on the use of physician services and on mortality in the workingage population.J Clin Epidemiol 1997;50:517-528.

15. Matsumura S. Perceived health status as predictor of utilization of health-care resources and the number of sick-leave days in Japan [Abstract]. Qual Life Res 2000;9:1063.

16.Wang Q, Bourbeau J. Outcomes and health-related quality of life following hospitalization for an acute exacerbation of COPD. Respirology 2005; 10:334-440

17. Schoofs N, Bambini D, Ronning P, Bielak E, Woehl J. Death of a lifestyle: The effects of social support and health care support on the quality of life of persons with fibromyalgia and/or chronic fatigue syndrome. Orthop Nurs 2004;23:364-374

18. Kahana E, Lawrence RH, Kahana B, Kercher K,Wisniewski A, Stoller E, et al. Long-term impact of preventive proactivity on quality of life of the old-old. Psychosom Med 2002;64:382-394.

19. Gallegos-Carrillo K, Durán-Arenas L, López-Carrillo L, López-

Cervantes M. Factores asociados con las dimensiones de calidad de vida del adulto mayor en Morelos. Rev Invest Clin 2003;55:260-269.

20. Gleich GS. Health maintenance and prevention in the elderly. Prim Care 1995;22:697-7| I

21. Stuck AE, Egger M, Hammer A, Minder CE, Beck JC. Home visits to prevent nursing home admission and functional decline in elderly people: Systematic review and Meta regression analysis. JAMA 2002;287:1022-1028. 22. van Haastregt JC, Diederiks JP, van Rossum E, de Witte LP, Crebolder HF. Effects of preventive home visits to elderly people living in the community: systematic review. BMJ 2000;320:754-758.

23. Elkan R, Kendrick D, Dewey M, Hewitt M, Robinson J, Blair M, et al. Effectiveness of home based support for older people: a systematic review and meta-analysis. BMJ 200 I;323:719-725.

24. Reyes-Beaman S, Beaman PE, Garcia-Peña C,Villa MA, Heres J, et al. Validation of a modified version of the Mini-Mental State Examination (MMSE) in Spanish.Aging Neuropsychol Cognition 2004: I I: I- I I. 25. Ware JE Jr, Sherbourne CD. The MOS 36-item short-form health survey (SF-36): I. Conceptual framework and item selection. Med Care 1992:30:473-483.

26. Zúñiga MA, Carrillo-Jiménez GT, Fox PJ, Gandek B, Medina-Moreno MR. Evaluación del estado de salud con la Encuesta SF-36: resultados preliminares. Salud Publica Mex 1999;4I:I I0-I I8.
27. Duran-Arenas L, Gallegos-Carrillo K, Salinas-Escudero G, MartínezSalgado H.Towards a Mexican normative standard for measurement of the Short Format 36 health-related quality of life instrument. Salud Publica Mex 2004:46:306-315.

28. Ware JE, Snow K, Kosinki M, Gandek B. The SF-36 Health Survey: Manual and Interpretation Guide. Boston, MA, USA: New England Medical Center Health Institute, 1993.

29. World Health Organization. Declaration of Alma Ata. International Conference on Primary Health Care. Alma Ata USSR:WHO, 1978. 30. Wong R, Figueroa ME. Morbilidad y utilización de servicios de salud entre población de edad avanzada: Un análisis comparativo. (ENSA-2000). Papeles de Población 1999;5:I03-I24.

3I.Wong R, Espinoza M, Palloni A. Adultos mayores en un contexto socioeconómico amplio: salud y envejecimiento. Salud Publica Mex 2007;49(suppl 4):S436-S447.

32. Instituto Nacional de Salud Pública-Secretaría de Salud. Encuesta Nacional de Salud (ENSA 2000), México, DF: INSP-SSA, 2000.

33. Borges-Yañez SA, Gomez-Dantes H. Use of health services by a population of 60-year olds and older in Mexico. Salud Publica Mex 1998:40:12-23.

34. Gómez-Dantés H,Vázquez JL, Fernández-Cantón S. La salud de los adultos en el Instituto Mexicano del Seguro Social. In: Muñoz O, GarcíaPeña C, Durán-Arenas L. La salud del adulto mayor: temas y debates. México, DF: Instituto Mexicano del Seguro Social, 2004:45-6I.

35. Theander E, Edberg AK. Preventive home visits to older people in Southern Sweden. Scand J Public Health 2005;33:392-400. 36. Damian J, Ruigomez A, Pastor V, Martin-Moreno JM. Determinants of self assessed health among Spanish older people living at home.J Epidemiol Community Health 1999;53:412-4I6.

37. Mutchler JE, Burr JA. Racial differences in health and health care service utilization in later life: the effect of socioeconomic status.J Health Soc Behav 1991:32:342-356.

38. Blaum CS, Liang J, Liu X.The relationship of chronic disease and health status to the health services utilization of older Americans. J Am Geriatr Soc 1994;42:1087-1093.

39. Kahana E, Kahana B. Contextualizing successful aging: new directions in an age-old search. In: Settersen RA Jr, ed. Invitation to the life course: toward a new understanding of late life. New York: Baywood Publishing, 2003:225-255

40. Regidor E, Barrio G, de la Fuente L, Domingo A, Rodríguez C,Alonso J. Association between schooling and health-related quality of life in Spanish adults.J Epidemiol Community Health 1999;53:75-82.

4I.Alonso J, Ferrer M, Gandek B,Ware JE Jr,Aaronson NK, Mosconi P, et al. Health-related quality of life associated with chronic conditions in eight countries: results from the International Quality of Life Assessment (IQOLA) Project. Qual Life Res 2004; I3:283-298.

42. Michelson H, Bolund, C, Brandberg Y. Multiple chronic health problems are negatively associated with health-related quality of life (HRQL) irrespective of age. Qual Life Res 2000; 9:1093-II04.

43. Aydemir O, Ozdemir C, Koroglu E.The impact of co-morbid conditions on the SF-36: a primary-care-based study among hypertensives. Arch Med Res 2005;36:|36-|4|. 